\title{
Heurística Positiva no Programa de Pensamento Econômico Pós-Keynesiano: Uma Visão a partir das Ideias de Minsky
}

\author{
Positive Heuristic in Post-Keynesian Economic Research \\ Program: An Approach Related to Minsky ldeas
}

João Felippe Cury Marinho Mathias*

Resumo: O objetivo deste do trabalho é apresentar a teoria pós-keynesiana à luz da metodologia proposta por Lakatos (1978). O objetivo específico é apresentar as reformulações e os aperfeiçoamentos do Programa de Pesquisa Científico (PPC) pós-keynesiano e as contribuições para uma heurística positiva relativas às ideias de Hyman Minsky. O trabalho se apoia na hipótese de que os desenvolvimentos das ideias de Minsky contribuem para a concepção de uma heurística positiva no programa de pesquisa pós-keynesiano.

Palavras-chave: Programa de pesquisa científico. Heurística positiva. Minsky.

Abstract: The objective of this work is to present Keynesian Theory according to the methodology proposed by Lakatos (1978). The specific objective is to present the improvements inside Post-keynesian Scientific Research Program (SRP) and the contributions to a positive heuristic related to Hyman Minsky ideas. This work supports the hypothesis that Minsky developments ideas contribute to the generation of a positive heuristic inside Keynesian Research Program.

Keywords: Scientific research program. Positive heuristic. Minsky.

JEL Classification: B2; B22.

\section{1 lntrodução}

Após quase quatro décadas de franco declínio e marginalização no debate econômico e no ensino de Economia em boa parte do mundo, o programa de pesquisa keynesiano parece dar indícios de que está vivo e ainda pode apresentar explicações consistentes sobre os fenômenos macroeconômicos. O prêmio Nobel

Professor adjunto de Macroeconomia do Instituto de Economia da Universidade Federal do Rio de Janeiro (UFRJ). E-mail: mathias@ie.ufrj.br 
de Economia de 2008, Paul Krugman, afirma na conclusão de seu artigo num dos principais jornais dos Estados Unidos a respeito dos motivos pelos quais os economistas erram tanto em suas previsões:

So here's what I think economists have to do. First, they have to face up to the inconvenient reality that financial markets fall far short of perfection, that they are subject to extraordinary delusions and the madness of crowds. Second, they have to admit — and this will be very hard for the people who giggled and whispered over Keynes - that Keynesian economics remains the best framework we have for making sense of recessions and depressions. Third, they'll have to do their best to incorporate the realities of finance into macroeconomics. (KRUGMAN, 2009, p. 11).

Outros autores chamam atenção para a redescoberta do pensamento de Keynes. Falando especificamente sobre o "Retorno de Keynes", Carvalho (2009, p. 92) diz:

[...] a riqueza de suas idéias pareça estar sendo redescoberta em quase todo o mundo, como resultado da crise econômica em curso. Um debate macroeconômico que havia sido dado como morto quando conceitos como expectativas racionais, hipótese dos mercados eficientes, etc. foram usados para demonstrar a irrelevância das políticas monetárias e fiscais nos delirantes anos de 1980, ressurge das cinzas das estratégias liberalizantes adotadas nos últimos trinta anos em quase todo o mundo.

Convém lembrar das distintas correntes do que se conhece como keynesianismo, tendo como dois grandes expoentes o velho-keynesianismo (ou keynesianismo ortodoxo $)^{1}$ e o pós-keynesianismo. Este trabalho se afilia a este último, em particular enfatiza a contribuição do pensamento de Hyman Minsky.

Skidelsky (2009, p.xiii), ao chamar a atenção para um dos mais violentos colapsos econômicos dos últimos tempos, destaca a pobreza das teorias econômicas do mainstream no que se refere à explicação da crise e conclui: "And we also have precious littles idea about how to stop a succession of such crises bearing down on us in future. To get a handle on these issues we need John Maynard Keynes".

Com efeito, parece claro que o momento histórico referente ao período da grande crise financeira de 2007 e 2008 mostrou-se favorável ao ressurgimento das ideias de Keynes, particularmente àquelas associadas ao programa de pesquisa

$1 \quad$ Ou ainda keynesianismo da síntese neoclássica. Snowdon e Vane (2005) apresentam com riqueza de detalhes a "escola keynesiana ordodoxa" sendo esta composta por seguidores do arcabouço IS-LM de Hicks. São citados como economistas keynesianos da tradição ortodoxa Modigliani, Patinkin, Hansen, Phillips, Tobin, dentre outros. Adiante este ponto será retomado. 
pós-keynesiano. Segundo Paula e Ferrari Filho (2010, p. 4) o mundo vive, após a crise de 2007-2008, "tempos keynesianos"2:

[...] está claro que vivemos "tempos keynesianos", embora os contornos da política econômica que assegure a saída definitiva da crise e, sobretudo, para um mundo pós-crise não estejam muito claros no debate econômico atual [2010]. Afinal, os sinais de recuperação econômica mundial têm sido contrastados com sinais preocupantes, como a crise européia dos chamados PIIGS (Portugal, Itália, Irlanda, Grécia e Espanha), e o fato de que a moderada recuperação econômica no mundo tem sido acompanhada de hesitante diminuição no desemprego.

O próprio pensamento mainstream ${ }^{3}$, ou parte dele, reconhece a incapacidade de suas abordagens teóricas darem conta da interpretação das causas e dos desdobramentos da crise, que se estendem desde 2007 tendo grande impacto na Europa e nos Estados Unidos. A posição do staff do FMI em nota é taxativa: Blanchard, Dell'Ariccia e Mauro (2010, p. 3) afirmam, na introdução da nota: "The crisis clearly forces us to question our earlier assessment". Nesse sentido, abriu-se um espaço para o retorno de algumas ideias defendidas pelo programa de pesquisa pós-keynesiano 4 .

Segundo Lakatos (1978), o programa de pesquisa científico (PPC) é caracterizado por regras metodológicas: algumas indicam os caminhos de investigação a se evitar (heurística negativa), outras, os caminhos a seguir (heurística positiva). É

2 Convém lembrar que em vários países da Europa e nos Estados Unidos ainda em 2010 e 2011 eram sentidas as consequências da crise de 2007/2008. Skidelsky (2009, p. xiv) era cético quanto às propostas de reforma financeira internacional, o que, segundo ele, não protegeria a economia de futuras crises: "Today, the first lesson appears to have sunk in: various bailout and stimulus packages have stimulated depressed economies sufficiently to give us reasonable expectation that the worst of the slump is over. But, judging from recent proposals in the United States, the United Kingdom, and European Union to reform the financial system, it is far from clear that the second lesson has been learned. A few cosmetic reforms, it now seems to be agreed, are all that is needed. This is to set the scene for the next crisis".

3 Entende-se por pensamento mainstream as ideias conhecidas pelo chamado "novo consenso macroeconômico", que, segundo Paula e Ferrari Filho (2010), se baseia nos seguintes princípios: 1) fixação de um único objetivo para a política monetária: obtenção de uma taxa de inflação baixa e estável; 2) a política monetária, conduzida sob um regime de metas de inflação, deve ter como único instrumento a taxa de juros de curto prazo; 3) o único objetivo da política fiscal deve ser a estabilização da dívida bruta do setor público como proporção do PIB; e 4) a regulação financeira deve ser pensada de forma independente dos impactos macroeconômicos da mesma, focando apenas em instituições e mercados.

4 Segundo os citados autores foram várias as lições da crise, quais sejam: i) a baixa inflação pode ser necessária, mas não suficiente; ii) a baixa inflação limita o escopo da política monetária nas recessões deflacionárias; iii) a intermediação financeira importa; iv) a política fiscal contracíclica é uma ferramenta importante; v) a regulação macroeconômica não é neutra; vi) a necessidade de se reinterpretar a "Grande Moderação". 
possível evidenciar a heurística positiva no PPC pós-keynesiano? Pode-se considerar esse PPC progressivo ${ }^{5}$ ?

Com efeito, o objetivo geral deste trabalho é apresentar a teoria pós-keynesiana à luz da metodologia proposta por Lakatos $(1978)^{6}$. O objetivo específico é apresentar as reformulações e os aperfeiçoamentos do PPC pós-keynesiano e as contribuições para uma heurística positiva relativas às ideias de Hyman Minsky. $\mathrm{O}$ trabalho se apoia na hipótese de que os desenvolvimentos das ideias de Minsky aqui neste trabalho dividido em três momentos - contribuem para a concepção de uma heurística positiva no programa de pesquisa pós-keynesiano.

Dessa forma, busca-se evidenciar o acréscimo de conteúdo empírico a partir de alterações (desenvolvimentos) teóricos consistentes. Tal reformulação permite o desenvolvimento de um "cinturão protetor" de modelos teóricos que sejam capazes de produzir resultados ou "previsões" que possam ser contrastados com os fatos observados. Para buscar respostas é feita uma extensa revisão bibliográfica dos pensadores que, a partir do núcleo duro do pensamento keynesiano exposto na Teoria Geral do Emprego do Juro e do Dinheiro, livro publicado em 1936 (KEYNES, 1970), desenvolveram diversas abordagens com o objetivo de aperfeiçoamentos teóricos.

O artigo está estruturado em mais três seções e as considerações finais. A próxima seção tem por objetivo mostrar os conceitos desenvolvidos por Lakatos a respeito dos programas de pesquisa científicos, bem como apresentar o PPC pós-keynesiano e a contribuição do pensamento de Minsky. A seção 3 apresenta uma visão geral do pensamento de Minsky e algumas limitações de sua abordagem. À guisa de mostrar as reformulações e a heurística positiva no PPC keynesiano, a seção 4 apresenta os avanços na abordagem de Minsky, dividindo-os em três momentos. Finalmente são apresentadas as considerações finais e as conclusões do trabalho.

\section{Programa de Pesquisa Cientiffico}

Esta seção apresenta as ideias gerais desenvolvidas por Lakatos (1978) do que se entende por Programa de Pesquisa Científico (PPC), de modo a apresentar as ideias centrais do PPC pós-keynesiano, foco deste trabalho. Mais especificamen-

5 Um PPC progressivo é aquele que continuamente tem sucesso ao fazer novas previsões, sistematicamente respondendo pela apresentação de dados fora das amostras (BLAUG, 1974, p.74).

6 Oreiro (2008) utiliza a perspectiva de Lakatos na análise do pensamento pós-keynesiano. Para Oreiro (2008, p. 21-22): “[...] o pensamento pós-keynesiano pode ser perfeitamente definido como um programa de pesquisa no sentido de Lakatos, possuindo um núcleo duro de proposições analíticas, um conjunto de questões resolvidas no interior do paradigma, bem como possibilidades de desenvolvimento futuro do mesmo". Mathias (2003) apresenta as ideias do PPC pós-keynesiano na construção de uma abordagem sistêmica de crises cambiais. 
te é apresentada a contribuição de Hyman Minsky ao PPC pós-keynesiano e à literatura econômica.

\subsection{As Ideias Gerais de um Programa de Pesquisa Cientifico}

Lakatos (1978) apresenta uma metodologia de programas de investigação científica, ou programa de pesquisa científica (doravante PPC) ${ }^{7}$. Segundo Lakatos (1978, p. 55), todos os programas de investigação científica podem ser caracterizados pelo seu núcleo duro ou heurística negativa. A heurística negativa do programa impede a orientação do modus tollens para este núcleo ${ }^{8}$. Assim, segundo Lakatos, devem ser articuladas hipóteses auxiliares que formem o "cinturão protetor" do núcleo duro e, em seguida, reorientar o modus tollens para estas hipóteses. Assim, a heurística negativa especifica o núcleo duro do PPC que é irrefutável pelas decisões de seus proponentes.

Sobre o núcleo duro de um PPC, também afirma Blaug (1999, p. 75): “[...] se os PPCs estão constantemente evoluindo dentro do esforço para lidar com anomalias e para abranger novos fenômenos, segue-se que alguns de seus componentes devem permanecer mais ou menos os mesmos ou estaríamos na realidade nos deparando com PPCs inteiramente novos; em resumo, deve haver algo como um núcleo central ou parte relativamente rígida em qualquer PPC".

Mas, segundo Lakatos (1978), os PPCs são também caracterizados por sua heurística positiva, que consiste num conjunto parcialmente articulado de sugestões ou conselhos sobre como modificar, desenvolver, as "variantes refutáveis" do programa de investigação, como alterar e tornar mais sofisticado o cinturão protetor refutável. Um ponto importante de heurística positiva é a possibilidade do PPC novamente avançar. Com efeito, segundo Lakatos (1978, p. 60): "A heurística positiva é assim, em geral, mais flexível do que a heurística negativa. Além disso, acontece ocasionalmente que, quando um programa de investigação entra numa fase degenerativa, uma pequena revolução ou uma alteração criativa na sua heurística positiva o faz de novo avançar".

Vieira (2002, p. 28) ${ }^{9}$ sugere que a partir do desenvolvimento de hipóteses auxiliares ("cinto" ou "cinturão protetor"), o PPC pode voltar a progredir:

$7 \quad$ O início do trabalho de Lakatos (1978) se propõe a comparar as ideias de Karl Popper e Thomas Kuhn. Como não é objetivo deste trabalho o debate acerca da Filosofia da Ciência, as ideias de falseabilidade (Popper) e de paradigma (Kuhn), não serão aqui apresentadas. Para maiores detalhes ver Lakatos (1978) e Blaug (1999).

8 Segundo Blaug (1999) se, por um lado, afirmar o antecedente (modus ponens) é uma falácia lógica, negar o consequente (modus tollens) será sempre logicamente correto. Não há lógica da prova, mas da contestação.

9 O trabalho de Vieira (2002) se baseia no referencial de Thomas Kuhn, isto é, a noção de paradigma, aplicada à economia. 
Já quando se trata do cinto protetor, Lakatos admite a refutação das teorias complementares ao núcleo que o compõem e ressalta o papel da crítica a essas teorias como sendo inclusive favorável à manutenção do PPC à medida que os cientistas que o desenvolvem podem, às vezes, converter aparentes derrotas do programa de pesquisa em triunfos esplendorosos, reafirmando (e até estendendo) a abrangência de suas teorias.

Cabe, portanto, identificar o núcleo duro e o cinturão protetor do PPC póskeynesiano, o que é feito a seguir.

\subsection{O PPC Pós-Keynesiano}

Blaug (1999, p. 281) analisa a contribuição do pensamento keynesiano à luz do aparato criado por Lakatos. Em suas palavras:

A revolução keynesiana representou uma mudança de maré sem paralelo na história do pensamento econômico: nunca um novo programa de pesquisa havia conquistado a profissão de economia de forma tão rápida e completa. É brincadeira de criança explicar as concepções de hard core e a heurística positiva e negativa da economia keynesiana e não há muita dúvida de que não se tratava apenas de uma teoria e sim de um programa de pesquisa para se trabalhar com um ponto de vista distinto dentro de um amplo número de diferentes áreas da economia.

Desde antes da morte de Keynes, em 1946, até os anos 1970, um grande e heterogêneo grupo de seguidores formou a escola keynesiana. Entre eles, destacam-se os keynesianos da chamada "síntese neoclássica", ou os velhos-keynesianos ${ }^{10}$, e os pós-keynesianos da primeira vertente ${ }^{11}$. Ao que parece, é essa a economia keynesiana a que Blaug (1999) se refere. Segundo Blaug (1999), a economia keynesiana foi um programa de pesquisa progressivo no sentido proposto por Lakatos ao longo dos anos 1930, 40 e 50: previu fatos novos, os quais foram corroborados por seus seguidores quase logo em seguida a seus anúncios. No entanto, o programa de pesquisa keynesiano começou e degenerar nos anos

10 Hicks, em seu artigo "Mr. Keynes and the Classics: A suggested interpretation”, deu início a um leque de interpretações de cunho neoclássico das ideias de Keynes. A síntese neoclássica que veio, durante as duas décadas que se seguiram à publicação da Teoria Geral, desconsiderava o caráter geral da teoria keynesiana.

11 O trabalho de Oreiro (2008) apresenta um histórico do surgimento da escola pós-keynesiana. Para este autor, a primeira vertente dessa escola se desenvolveu em torno da temática do crescimento e distribuição de renda; tendo sua origem nas contribuições seminais de Harrod e Domar, as quais são uma tentativa de extensão para o longo-prazo dos resultados Keynes na Teoria Geral. Outros modelos foram desenvolvidos por Kaldor e Pasinetti. Há, ainda, a contribuição de Joan Robinson. 
1950. Blaug (1999) cita uma série de revisões na economia keynesiana e aponta alguns autores importantes como Modigliani, Tobin, Baumol, Harrod, Domar, entre outros ${ }^{12}$. Aqui parece constituir-se um cinturão protetor a partir do desenvolvimento de hipóteses auxiliares. A partir dos anos 1950/60, ao mesmo tempo em que o PPC keynesiano se tornava degenerativo, o PPC monetarista se tornava progressivo.

No prefácio da Teoria Geral, Keynes (1970, p. 9) faz questão de chamar atenção para a concepção de um novo hard core em seu pensamento: "Desejaria que esta [teoria] pudesse ter sido menos longa, mas pareceu-me essencial não apenas explicar minha maneira de ver como ainda esclarecer os pontos em que ela se afasta da teoria dominante". Nesse sentido, convém destacar a retomada do núcleo duro das ideias de Keynes pela segunda vertente do pós-keynesianismo, surgida nos anos 1970, na qual se insere Hyman Minsky. Para essa vertente, o aspecto fundamental do pensamento keynesiano estaria na análise dos efeitos da existência da incerteza não probabilística sobre o comportamento e as decisões dos agentes econômicos, em particular, as decisões sobre a determinação do ritmo e da forma na qual a riqueza é acumulada (OREIRO, 2008). A partir dessa perspectiva é possível estabelecer o núcleo duro das ideias de Keynes, segundo a escola pós-keynesiana.

Oreiro (2008, p. 5) desenvolve a ideia de visão de mundo apresentada por Schumpeter ${ }^{13}$ e cita: "Para pós-keynesianos, contudo, Keynes teria desenvolvido ao longo da sua Teoria Geral e dos seus demais escritos acadêmicos uma nova visão de mundo no sentido de Schumpeter, a qual seria uma ruptura radical com relação ao pensamento neoclássico prevalecente até então". A visão de mundo de Keynes estaria resumida no conceito que define os princípios de economia monetária de produção, conclui Oreiro (2008, p.7): "Esses princípios podem ser entendidos como o núcleo do programa de pesquisa pós-keynesiano, ou seja, aquele conjunto de proposições cuja veracidade não é objeto de investigação, sendo aceito como verdade irrefutável por todos aqueles adotam o referido programa".

Segundo Carvalho (2009) Keynes não se dedicou a um "caso" teórico. Seu objetivo era, ao contrário, sugerir que os fundamentos de uma economia empresarial não são adequadamente retratados pela economia clássica. Para Keynes, os clássicos não conseguiam explicar a depressão, realmente, mas também não conseguiam explicar os estados de euforia dessa economia ou, mesmo, qualquer outro estado satisfatoriamente. Em sua visão isto era uma consequência da inadequada identificação dos mecanismos fundamentais de operação de economias

12 Oreiro (2008) apresenta um breve histórico da evolução das ideias dos seguidores de Keynes na seção 2 de seu artigo.

13 Segundo Oreiro (2008), visão de mundo é definida por Schumpeter como o ato cognitivo préanalítico que define o conjunto de fenômenos que devem ser objeto de análise sistemática. 
empresariais. Com efeito, aqui parece residir a grande contribuição do programa de pesquisa inaugurado por Keynes.

Levando em consideração os efeitos da existência da incerteza não probabilística ${ }^{14}$ sobre o comportamento e as decisões dos agentes econômicos, Carvalho (2009) consegue, em seu texto, sintetizar o núcleo duro do que ele chama de economia de Keynes, a partir das seguintes proposições:

a) Não neutralidade da moeda. Segundo Keynes, a não neutralidade da moeda se apoia na relação entre o valor da moeda como um ativo, isto é, como uma forma de riqueza (um veículo que transfere um direito sobre a renda social do presente para uma data futura) e o valor dos outros ativos, das outras formas de riqueza, não apenas os ativos financeiros, mas também os ativos de capital real. A escassez relativa de ativos monetários, demandados por sua liquidez, reduz a demanda e o preço de ativos como, por exemplo, bens de capital, e, assim, influenciam as posições de longo período da economia.

b) $\mathbf{O}$ conceito de liquidez. Liquidez significa a possibilidade de converter a riqueza presente em poder de compra para usá-lo na aquisição de outras formas de riqueza. Existe um prêmio de liquidez a ser computado no valor de um ativo quando, ao comprá-lo, o comprador reconhece que pode desejar desfazer essa transação no futuro, especialmente se condições imprevisíveis no momento da decisão vierem a prevalecer.

c) Não neutralidade ${ }^{15}$ da valoração de ativos. Trata-se do reconhecimento da conexão entre moeda, prêmio de liquidez e preço dos ativos. Na economia de Keynes, o investimento depende dos preços dos ativos reais relativamente aos preços dos ativos financeiros e do nível de preço dos bens correntemente produzidos. $\mathrm{O}$ preço de demanda de um ativo qualquer é o valor presente dos ganhos que se espera obter da sua posse. Maiores preços de demanda significam maiores expectativas de retornos. Para Carvalho (2009), a não neutralidade da moeda e a não neutralidade do mercado de ativos são, na economia de Keynes, duas faces da mesma moeda.

d) Estado de confiança. A confiança numa determinada expectativa depende de quanto dessa expectativa é explicada por suposições, em vez de informações, e da confiança nessas mesmas suposições. A mesma expectativa quantitativa pode conduzir a diferentes decisões, dependendo da confiança que o tomador de decisões tenha na suas suposições. Variações no estado de confiança, por sua vez, refletem, em grande parte, a experiência de cada um.

14 Dequech (1999, p. 67-68) define com clareza a ideia de incerteza: "It is enough at this point to define uncertainty as a situation in which knowledge, due to a paucity of evidence, is incomplete and unreliable as a guide to conduct. Uncertainty then implies the absence of a fully reliable probability distribution. In its strongest sense, uncertainty implies indeterminacy of the future, as the future is yet to be created by people's decisions".

15 Aqui a não neutralidade é um crítica à hipótese dos mercados eficientes. Para Carvalho (2009), a tradição da hipótese dos mercados eficientes baseia-se na ideia de que a precificação de ativos é neutra em relação ao total da poupança e do investimento de uma economia. 
e) Relação entre estado de confiança e demanda efetiva. Um colapso do estado de confiança conduz a um aumento da preferência pela liquidez que, por seu turno, conduz à redução dos preços de demanda dos ativos menos líquidos, atingindo especialmente os ativos de capital real, contraindo investimentos e, através do multiplicador de consumo, contraindo a renda e o emprego agregados.

f) O papel dos gastos do governo na sustentação da demanda agregada. Quando a demanda privada se contrai, em resultado desse processo, a manutenção do nível de atividades só pode ser obtida se alguma fonte alternativa de demanda for encontrada, ou seja, numa economia fechada, os gastos do governo.

g) A estabilidade e as economias empresariais. A visão da economia de Keynes é a de que nos mercados financeiros as tendências desintegradoras são particularmente atuantes, para cuja contenção é fundamental a existência de métodos de regulação e supervisão financeiras relativamente rigorosos.

Ao interpretar a análise de Keynes, Vidotto (2008, p. 49), também sintetiza o núcleo duro do PPC pós-keynesiano lembrando que a teoria econômica de Keynes não é redutível a uma teoria pura ou a um modelo. Em suas palavras:

Primeiro, articulou o princípio da demanda efetiva com a lógica que preside o processo decisório dos detentores de riqueza e renda, sublinhando nessa articulação a centralidade exercida pela formação de expectativas num ambiente econômico marcado pela incerteza. Segundo, o dilema entre diversos tipos de gastos de investimento e aplicações financeiras o conduziu à identificação do que chamou de mercados financeiros organizados.

Assim sendo, as ideias supracitadas constituem o núcleo duro do PPC póskeynesiano, base do desenvolvimento das ideias de Minsky. Conforme lembra Lourenço (2005, p. 10), o próprio Minsky, no capítulo 3 de sua obra John Maynard Keynes, de 1975, aponta "[...] os elementos que considera basilares em Keynes, e que também podem ser considerados como conceitos essenciais à sua própria obra: 1) tempo e incerteza; 2) desequilíbrio; e 3) a perspectiva cíclica e o investimento". Tais elementos fazem parte do núcleo duro do PPC pós-keynesiano ${ }^{16}$.

Hyman Minsky fez várias contribuições ao PPC pós-keynesiano. A principal delas foi a Hipótese da Instabilidade Financeira (HIF). Segundo Minsky (1992a, p. 1): "The financial instability hypothesis has both empirical and theoretical aspects. The readily observed empirical aspect is that, from time to time, capitalist's economies exhibit inflations and debt deflations which seem to have the potential to spin out of control". A seção a seguir apresenta a contribuição de Hyman Minsky para a literatura econômica.

16 Tymoigne (2008, p. 3) dá pistas da contribuição de Minsky: "Following Keynes, Minsky stated that unfair distribution, economic instability and unemployment were structural problems of market mechanisms, and so he promoted a form of capitalism that significantly involves the government". 


\subsection{A Contribuição de Minsky à Literatura Econômica e ao PPC Pós-Keynesiano}

$\mathrm{Na}$ apresentação do texto Financiamento e Lucros de Minsky et al. (1992, p. 3) explicitam com clareza a contribuição deste autor: "Minsky viu mais longe do que Keynes, quando estabeleceu que a decisão de investir só pode ser tomada juntamente com a decisão de como financiar essa compra de ativos de capital". Aqui parece estar evidenciada a heurística positiva dentro do PPC pós-keynesiano, tornando suas hipóteses auxiliares ("cinturão protetor") muito mais sofisticadas.

Taylor e O'Connell (1985, p. 871) falam sobre a influência das ideias Minsky com destaque para a análise das crises financeiras:

Hyman Minsky's ideas about financial crises are influential. For example, he provides much of the theoretical foundation for Charles Kindleberger's [1978] well-known book on Manias, Panics, and Crashes. But for all his citations in the specialist literature, Minsky's work has never been elaborated formally, and he is scarcely noticed in the textbooks.

Ao discutir o pensamento de Minsky e os desafios da metodologia aplicada à economia contemporânea, Foley (1998, p. 1) reconhece a importância das ideias de Minsky ${ }^{17}$ : "The fertility of Minsky's insights and the resonance they met in the practical worlds of finance and policy-making suggest that the examination of Minsky's work offers a valuable critical perspective on modern economic method". O mesmo autor chama a atenção para os insights de Minsky, associado aos eventos históricos reais ao ciclo financeiro:

His theses on financial fragility and instability stem from his vision of the financial process as an essentially human confrontation of the present with the future, mediated by all the psychological baggage humans carry to major life decisions: their self-deception, opportunism, and insecurity as well as their faith, imagination, and steadfastness. From this vision Minsky drew genuine and valuable insight about real historical events, and gained some perspective on the deeper rhythms of financial life (FOLEY, 1998, p. 4).

Lourenço (2005, p. 1) consegue sintetizar com clareza as contribuições de Minsky (1975, 1982, 1986, entre outros textos) para a literatura econômica ${ }^{18}$, cujo legado foi:

17 Foley (1998) reconhece a relevância das ideias de Minsky, no entanto, ressalta que elas são mais influentes junto aos pelos formuladores de políticas e nas comunidades financeiras, que propriamente no meio acadêmico: "Hyman Minsky's work on financial fragility and the political economy of instability in advanced capitalist economies has had more influence in the policymaking and financial communities than among academic economists.

18 O autor apresenta, com riqueza de detalhes, extensa revisão bibliográfica explicitando a contribuição de Minsky em cada um dos trabalhos. 
a) uma interpretação "financeira" da Teoria Geral e uma crítica da interpretação convencional desta;

b) uma contribuição teórica fundamental, a hipótese de instabilidade financeira e outras subsidiárias, como sua teoria da inflação;

c) contribuições sobre dinâmica institucional, por exemplo, análise da atividade bancária, das inovações financeiras e dos bancos centrais;

d) contribuições à reconstituição histórica e interpretação das crises financeiras estadunidenses e mundiais, da Grande Depressão dos anos trinta às do início dos anos 90;

e) contribuições normativas, abarcando desde uma proposta bastante ampla de reformulação de toda política econômica e social até questões pontuais, como o exame dos bancos pelas autoridades regulatórias.

Porém, um dos objetivos do trabalho de Lourenço (2005) é verificar se a forma tradicional na qual a hipótese de instabilidade financeira foi exposta e popularizada é suficiente para lidar com o fenômeno das crises financeiras contemporâneas. Cabe, então, explicitar algumas das limitações da abordagem de Minsky e evidenciar algumas reformulações necessárias.

\section{Uma Visão Geral e Algumas Limitações da Abordagem de Minsky}

Hyman Minsky chamava atenção para a inerência da instabilidade numa economia capitalista moderna e a impossibilidade da sobrevivência de configurações incoerentes nesta. Minsky argumenta que as expansões cíclicas das transações econômicas capitalistas são, inevitavelmente, acompanhadas por fragilidades financeiras e, portanto, o capitalismo é recorrentemente sujeito a crises financeiras. Segundo Minsky (1992b, p. 11): "Como a instabilidade financeira é um aspecto dos importantes ciclos de negócios da história, uma teoria que explique a instabilidade financeira nos possibilitará entender porque a nossa economia é intermitentemente instável".

Portanto, deve-se à Minsky $(1975,1982,1986)$ a introdução das relações financeiras na teoria de investimento keynesiana. Este autor enfatizou o crescimento econômico acompanhado de fragilização da economia. A novidade foi incorporar a estrutura do passivo, ou seja, o financiamento da posição dos ativos. Em outras palavras, para Minsky interessa não só a estrutura dos ativos, mas também como se dá o seu financiamento, verificando a composição passiva.

A ideia é que cada unidade econômica é caracterizada por como, no seu portfólio, compatibiliza as datas e os valores dos pagamentos com as datas em que espera receitas suficientes para cumpri-los. O conceito de fragilidade financeira surge desta ideia de que há riscos de não compatibilização dos fluxos de entrada e saída de recursos. Significa o grau de prudência no endividamento dos agen- 
tes econômicos. Os riscos surgem de ambos os lados, tanto do credor, quanto do devedor.

A principal ideia oferecida pelo modelo de Minsky é apontar as possíveis implicações da incompatibilidade entre a maturidade dos ativos e dos compromissos assumidos pelos investidores, para a economia como um todo. De acordo com o modelo de Minsky, esse processo se inicia quando num período de boom ou crescimento há contínuas reduções nas margens de segurança, o que tem como consequência o aumento da fragilidade financeira.

Minsky demonstra que, nos períodos de rápido aumento do investimento, as expectativas otimistas oriundas do boom podem levar a reduções nas margens de segurança, por parte das empresas tomadoras ou das instituições emprestadoras. Em outras palavras, a hipótese de fragilidade financeira reconhece a tendência de investidores em aumentar seus níveis de endividamento em momentos de otimismo. Costa (1992, p. 79) lembra de uma das características básicas da obra de Minsky, aqui enfatizada neste trabalho: "[...] é a ênfase colocada na inerência da instabilidade em uma economia capitalista moderna, onde jogam papel importante as instituições e as relações financeiras".

A abordagem da decisão de investir e financiar o investimento como parte integrante da composição do portfólio, num estado de incerteza, é peça central na análise de Minsky. A fonte de flutuações cíclicas está na instabilidade do investimento. A origem desta está na incerteza que cerca as decisões dos indivíduos e das firmas, numa economia capitalista. A incerteza surge porque essas decisões são descentralizadas, não coordenadas, e podem resultar em processos de geração de incoerências, através do confronto de planos incompatíveis.

Minsky elaborou uma tipologia que identifica o grau de fragilidade das posições patrimoniais dos investidores, segundo critérios de liquidez e solvência de suas carteiras que, ao longo de um ciclo de expansão creditícia, tendiam a transitar das formas mais seguras para as mais expostas a riscos. Segundo Minsky (2008b, p. 230): "There are three types of financing of positions in assets that can be identified in financial structure of our system: hedge, speculative and Ponzi finance. These financing regimes are characterized by different relations between cash payment commitments on debts and expected cash receipts due to the quasi-rents earned by capital assets or the debtor contractual commitments on owned financial instruments".

Dentro da terminologia de Minsky, as proporções das operações hedge, especulativas e Ponzi é que determinarão a fragilidade financeira macroeconômica. Estas são as três diferentes posturas financeiras que pode assumir um devedor. Quanto maior o peso de investidores especulativos ou Ponzi, mais vulnerável é a economia a mudanças nos mercados financeiros. Contrariamente, quanto maior o peso dos "hedgers", mais segura a economia estará em relação aos problemas financeiros. Em síntese, a tipologia de Minsky é descrita por Costa (1992) da seguinte forma: 
a) Hedge (protegido/defendido): agente que dá mais valor a evitar a bancarrota. Compóe seu portfólio de maneira a sempre se manter solvente, com seus valores patrimoniais do ativo superiores aos do passivo, e com as suas receitas previstas acima dos pagamentos a serem feitos em qualquer período. Mantém reservas líquidas, pois caso ocorra algum erro de cálculo, a solvabilidade é mantida. Uma economia hedge é financeiramente estável.

b) Especulativo: são também solventes, pois teriam seus valores patrimoniais do ativo maiores que os do passivo, porém em alguns subperíodos assumem eventuais prejuízos - quando as saídas monetárias em pagamento das dívidas são superiores às entradas monetárias esperadas -, especulando com a possibilidade de se refinanciarem. São insolvências temporárias, em que as receitas não cobrem o principal (a amortização), mas os juros são pagos. Dependem, portanto, do setor financeiro para a manutenção do crédito. No entanto, se a taxa de juros real (em relação aos próprios preços) se eleva demasiadamente, o retorno líquido do investimento não a compensa, agravando a fragilidade financeira.

c) Ponzi: de acordo com Minsky (2008b, p. 231): "A Ponzi-financing unit is similar to a speculative financing unit in that, for some near-term periods, the cash payment commitments on income account exceed the expected cash payment receipts on income account. Whereas the short period cash flows for speculative units are such that financing costs do not increase outstanding debt, for Ponzi units financing costs are greater than income, so that the face amount of outstanding debt increases: Ponzi units capitalize interest into their liability structure"

Sobre a importância das posturas no modelo de Minsky, lembra Carvalho (1992, p. 153): "Minsky's model of fragility is based on the identification of 'postures' or balance sheet choices investors can adopt to sustain their plans". Portanto, deve-se ressaltar que cada uma das posturas apresentadas por Minsky (hedge, especulativo e Ponzi) define uma trajetória particular de crescimento, dado que constroem uma situação financeira mais ou menos sólida, que capacitará à firma a planos de expansão mais ou menos ambiciosos. Durante o período de implementação dos planos de investimento, mudanças no ambiente externo (tais como um declínio nos determinantes do lucro ou uma mudança nas condições de financiamento) afetarão a firma de diferentes formas, de acordo com a estrutura de obrigações contratuais e o fluxo de receita.

Nesse sentido, um declínio na renda bruta de capital esperada (ou fluxo de renda esperado da utilização dos ativos de capital), ou uma piora nas condições de financiamento pode tornar uma unidade hedge em especulativa; um declínio na renda bruta de capital esperada, uma piora nas condições de financiamento ou um aumento nos custos financeiros pode tornar uma unidade especulativa numa unidade Ponzi. 
São inerentes na economia capitalista dois tipos de riscos: o do tomador e do emprestador. Segundo Minsky (2008a, p. 104), citando a Teoria Geral: "[...] the entrepreneur's or borrower's risk arises out of doubts in his own mind as to the probability of his actually earning the prospective yield for which he hopes [...] This [lender's risk] may be due to either a moral hazard i.e. voluntary default other means of escape, possibly lawful, from the fulfillment of the obligation [...]". Assim, em termos gerais o risco do tomador é aquele referente ao ativo financiado em sua compra. O risco do emprestador é aquele associado ao tomador não pagar nas condições estipuladas no contrato. Sobre este ponto lembra Bastos (1996, p. 223): “Se, por um lado, as decisões de compra de ativos instrumentais são muito arriscadas - nada garante que as expectativas de receitas que motivaram as compras sejam satisfeitas -, os compromissos financeiros estipulados nas dívidas, por outro lado, são certos, eis que garantidos por contratos".

Nessas circunstâncias, salienta Bastos, o descasamento entre a estrutura de ativos e a de passivos não se manifesta em crise, enquanto as convenções coletivas e a concorrência capitalista levarem os investidores a tomar novos créditos para financiarem novas compras de ativos instrumentais (desde que o sistema de crédito confie na capacidade de pagamento das dívidas, adiantando créditos).

O processo cíclico pode ser descrito como uma "instabilização da estabilidade". Em outras palavras, a fragilização da economia é fruto do bom comportamento da economia (estabilidade), no qual as expectativas são correspondidas uma vez que os contratos se cumprem e, por isto, as margens de segurança são diminuídas. A instabilização, portanto, ocorre na própria expansão da economia.

Minsky (1982) demonstra que se um aumento da fragilidade financeira causa uma deflação de dívida, esta pode levar a uma depressão. A deflação de dívida pode ser disparada pelos agentes que tentam vender seus ativos líquidos com o objetivo de aumentar sua liquidez (as firmas endividadas), de maneira a restabelecer as suas posições líquidas ou simplesmente para satisfazer mudanças de expectativas. A consequência desta corrida pela liquidez é um efeito sobre os gastos reais, uma vez que as taxas de juros são afetadas, alterando a disponibilidade de finance, funding e das expectativas de longo prazo empresariais (STUDART, 1995).

Na seguinte passagem, Foley (1998, p. 11) aborda o caráter persuasivo das ideias de Minsky e a validação delas com exemplos históricos:

Minsky had a lively sense of the importance of validating his insights with historical examples and parallels, and of linking general patterns to a detailed examination of institutional reality and the unfolding of particular episodes of financial life. Without this thick texture of well-informed argument, the financial fragility hypothesis would have been less persuasive and less well-crafted as a part of economic knowledge. 
Porém, vale a pena frisar que apesar de todo o avanço, a abordagem de Minsky foi construída levando em consideração um marco institucional específico, sobretudo aquele relacionado à economia dos Estados Unidos. Lourenço (2005, p. 3) capta com clareza o marco institucional da HIF:

Não é de surpreender, portanto, que a HIF tenha sido desenvolvida tendo por referência uma economia fechada - abordagem comum à grande maioria dos economistas de sua geração. Além disso, outros aspectos dão suporte adicional a esta escolha do autor. Primeiro, a relativa estabilidade das transações internacionais propiciadas pelo acordo de Bretton Woods; em segundo lugar, o relativo fechamento da economia estadunidense ao longo do período relevante do desenvolvimento da HIF; e em terceiro, o status diferenciado da economia estadunidense como banco do mundo, em decorrência da posição do dólar como moeda internacional.

Tal marco traz consigo limitações analíticas num mundo em que as relações econômicas e os marcos institucionais mudam continuamente. Bastos (1996) chama a atenção para as mudanças histórico-institucionais que caracterizaram os mercados financeiros internacionais nas décadas de 1970 a 1990. Tais mudanças teriam tornado defasadas as teorias para explicar o funcionamento do mercado financeiro. Com efeito, o autor indaga, com razão, se a hipótese de instabilidade financeira formulada por Minsky para investigar a relação entre o comportamento cíclico dos investimentos produtivos e do crédito bancário ainda preservaria validade heurística, uma vez que havia evidências de que o comportamento dos ciclos financeiros não estaria mais associado aos ciclos de investimento produtivo.

De acordo com Bastos (1996), a consideração de novas dinâmicas financeiras privadas faz com que se questione a hipótese de subordinação dos mercados de ativos líquidos aos mercados de ativos instrumentais e de crédito, com a qual Minsky formulou sua teoria de instabilidade financeira. Para Bastos (1996, p. 227):

Há evidências de que as transformações institucionais do sistema financeiro internacional, sentidas em alguns países mais que os outros, romperam essa subordinação: de uma atividade eminentemente conjuntural, as transações com ativos líquidos tornaram-se uma fonte permanente de renda para as corporações, instituições financeiras e aplicadores individuais [...] as fragilidades necessária e diretamente associadas ao comportamento dos investimentos produtivos e de sua forma de financiamento. Elas passaram a estar também associadas, cada vez mais, ao comportamento dos ciclos especulativos com ativos líquidos. 
Por causa da adaptabilidade aos novos marcos institucionais Lourenço (2005, p. 16) aponta ao mesmo tempo a robustez e a fragilidade da teoria de Minsky:

Não é difícil perceber que a robustez da teoria minskyana deriva-se justamente da plasticidade e adaptabilidade da HIF às mudanças nos marcos institucionais por que passou a economia capitalista, sem perda da coerência alicerçada em suas perspectivas fundamentais, transformando-a em poderosa ferramenta interpretativa de sua dinâmica. Da robustez, contudo, deriva a fragilidade: a própria sensibilidade da teoria às mudanças institucionais exige, sob pena de perda de relevância e pertinência, esforço revigorado e contínuo de atualização e renovação das formas de exposição da HIF.

A próxima seção tem por objetivo apresentar os esforços de readaptação/ reformulação da abordagem do Minsky.

\section{Avanços na Abordagem de Minsky}

Na verdade, há tempos a abordagem de Minsky vem sendo reformulada, revisitada ou aperfeiçoada. Muitos autores em períodos diferentes, por motivos distintos buscaram aperfeiçoar o arcabouço desenvolvido por Minsky. Muitas dessas adaptações têm a ver com as especificidades históricas. Como bem lembra Dymski (1998, p. 90):

O contexto estrutural - as particularidades históricas de tempo e lugar - de qualquer caso afetam crucialmente os resultados observados. Desta forma, compreender eventos por meio de uma análise keynesiana de dinâmica financeira significa focalizar não apenas o comportamento sob incerteza e a fragilidade financeira, mas também a especificidade estrutural desses eventos.

Com efeito, podem-se identificar vários momentos em que há desenvolvimentos da abordagem de Minsky, sobretudo aqueles referentes a crises cambiais e financeiras. Nos anos 1990, em função das crises cambiais e financeiras nos países emergentes do sudeste asiático, Rússia e Brasil, muitos trabalhos com inspiração em Minsky foram desenvolvidos (momento 2). A partir da crise subprime, em 2007, e seus desdobramentos e generalização de uma crise financeira em escala global, em 2008, muitas explicações foram apresentadas se apoiando na abordagem de Minsky (momento 3). Os dois momentos supracitados foram antecedidos por um momento de primeiros desenvolvimentos na abordagem de Minsky. A seguir, há uma divisão mais clara desses momentos, com a apresentação de algumas contribuições teóricas e empíricas. 


\subsection{Momento 1: Primeiros Desenvolvimentos}

Ao desenvolver a anatomia de uma crise financeira típica no capítulo 2 de seu livro Manias, Panics and Crashes, Kindleberger (1978, p.11) começa sua abordagem lançando mão das ideias de Hyman Minsky: "We start with the model of Hyman Minsky, a man with a reputation among monetary theorists for being particularly pessimistic, even lugubrious, in his emphasis on the fragility of the monetary system and its propensity to disaster". Trata-se de um dos primeiros desenvolvimentos das ideias de Minsky a partir do livro de John Maynard Keynes, de $1975^{19}$.

Taylor e O'Connell (1985) desenvolvem o modelo de Minsky a partir do pressuposto chave de que o nível de riqueza da economia é determinado em termos macroeconômicos, com o valor dos ativos das firmas refletindo o estado de confiança descontando as quase rendas do capital. O segundo pressuposto é que existe grande capacidade de substituição entre os passivos das firmas e o dinheiro do portfólio do público ${ }^{20}$.

Num esforço mais amplo de desenvolvimento das ideias de Minsky, Gatti e Gallegati (1990) exploram a emergência da instabilidade financeira dentro de um arcabouço teórico que simultaneamente mostra características do pensamento do Keynes, Kalecki e Minsky. Como citam Minsky, Gatti e Gallegati (1990, p. 358):

The interaction Minsky's financial theory of investment determination, Kalecki's theory of income distribution, and Keynes' theory of the demand of money - three different but not mutually incompatible pieces of economic theory - is the ultimate theoretical source of a remarkable richness of likely outcomes: whenever they exist, equilibria can be stable or unstable.

Hermann (1993) desenvolve, a partir das ideias de Minsky, um modelo de fragilidade financeira ligado ao setor público que se relaciona à noção de fragilidade externa. A autora lembra que na classificação proposta por Minsky o que basicamente distingue os graus das diferentes estruturas financeiras é a necessidade ou não de refinanciamento da dívida e a magnitude do eventual refinanciamento,

19 No Brasil, uma das primeiras adaptações das ideias de Minsky é feita por Lara Resende (1982). Lara Resende (1982) faz uma adaptação da tipologia de Minsky ao setor externo para analisar a crise externa enfrentada pelo Brasil no final dos anos 70 e início dos 80 . Segundo o autor (p. 44): "Os dois sucessivos aumentos dos preços do petróleo, os custos do ajustamento rápido e as facilidades associadas ao boom do mercado de crédito internacional levaram vários países a assumir financiamentos especulativos, na definição de Minsky, para suas contas externas: num horizonte de curto, ou mesmo médio prazo, o fluxo das receitas de exportações de bens e serviços é inferior ao fluxo de pagamentos de importações e serviços da dívida".

20 Gatti e Gallegati (1990) dizem que o trabalho de Taylor e O'Connell (1985) levou ao desenvolvimento de vários outros modelos ligados ao pensamento de Minsky. Esses modelos basicamente dividem o mesmo arcabouço analítico, baseado no papel chave da relação entre a taxa de lucro e a taxa de juros como elementos causadores da crise a la Minsky. Entre os trabalhos citados estão o de Semmler (1987), Lavoie (1986/7) e Downe (1987). 
durante o período de vigência do contrato. O grau de fragilidade externa de um país está intrinsecamente ligado às condições de viabilização da estrutura de pagamentos assumida. Pode-se dizer, grosso modo, que quanto maior for a participação de fatores exógenos na composição daquelas condições, maior é o grau de fragilidade externa do país.

Em meados dos anos 1990, começou a ser desenvolvida a relação das ideias de Minsky com o movimento de globalização ${ }^{21}$. Segundo Arestis (1996, p. 121): "These financial developments strengthen the link with Minsky's 'financial instability hypothesis' [the globalization of financial markets] in that the ability of financial institutions to create more debt enhances the degree of fragility of the system and thus the vulnerability of both banks and firms".

Foley (2003) busca modificar o modelo de Taylor e O'Connell (1985) e adapta a hipótese de fragilidade financeira de Minsky para uma economia aberta, com o objetivo de analisar as crises financeiras nas economias em desenvolvimento da década de 1990. Nas palavras de Foley (2003, p. 161): “The equations describing the financial dynamics of a firm apply equally well to a national economy, viewed as a collection of firms". De acordo com Foley (2003), choques positivos no investimento e na lucratividade em pequenas economias abertas em desenvolvimento engatilham uma entrada instável de capital que conduz a crises financeiras externas e internas, assim o resultado do déficit em conta corrente torna-se incontrolável. As crises financeiras tornam-se recorrentes nas economias abertas através da entrada de capital externo e do comportamento da taxa de juros, que agirá no sentido de ampliar o grau de endividamento do sistema econômico.

Kregel (1998, p. 4) corrobora a ideia de que o modelo de Minsky pode ser estendido para a análise de uma economia aberta:

Minsky's original analysis of the passage from financial fragility to financial instability is based on a change in domestic monetary policy or the persistence of stable domestic conditions. But the analysis is easily extended to an exogenous shock in exchange rates for companies operating in open trading systems and to banks borrowing and lending in international markets.

Para analisar a formação de economias de "bolha" na Califórnia, no Japão e na Coreia, Dymski (1998) buscou construir uma abordagem estrutural baseada nas ideias de Minsky, adaptando a uma economia aberta onde os fluxos entre as fronteiras importam.

21 Miranda (1995, p. 7) na apresentação da Revista Economia 8 Sociedade chamava a atenção para a incapacidade das antigas teorias de trazerem repostas aos novos problemas ligados ao processo de globalização: "Inicialmente a emergência dos euromercados e, posteriormente, os processos de liberalização e globalização financeira, a perda de importância relativa do sistema bancário para a criação creditícia e a proliferação de novos produtos financeiros, constituíram mudanças estruturais que tornaram precárias as antigas teorias para a apreensão da realidade contemporânea". 


\subsection{Momento 2: A Explicação das Crises Cambiais e Financeiras (1997-2001)}

Um segundo momento relacionado ao desenvolvimento de modelos a partir do arcabouço teórico e analítico proposto por Minsky ocorreu no contexto das grandes crises cambiais e financeiras do final dos anos 1990 (na Ásia, Rússia, Brasil e Argentina).

Foley (2003) desenvolve a abordagem de Minsky para economias abertas para estudar as crises dos anos 1990 nos países em desenvolvimento. Mathias (2003) faz esforço semelhante, com o objetivo de explicar a crise cambial brasileira de 1999.

O trabalho de Silva (2001) evidencia que os argumentos levantados no debate de crises cambiais no contexto das crises asiática, russa e brasileira são, na verdade, velhos argumentos tantas vezes levantados pela heterodoxia. Segundo a autora, os modelos de terceira geração reconhecem alguns aspectos das crises que sempre foram apontados por economistas 'heterodoxos', como por exemplo:

a) há o reconhecimento de que a instabilidade pode ter origem financeira em economias com sistemas financeiros pouco regulados;

b) há o reconhecimento de que a instabilidade financeira produz efeitos reais;

c) há o reconhecimento de que as crises cambiais são parte da instabilidade financeira. As crises cambiais são vistas como uma parte integral das crises gerais da economia. Esse é, também, o argumento por trás das interpretações pós-keynesianas das crises cambiais.

Arestis (2001) sustenta que o modelo de Minsky adaptado para economias abertas introduz um terceiro preço relativo, qual seja, a taxa de câmbio. Segundo esse autor, movimentos na taxa de câmbio são particularmente pertinentes no modelo de Minsky tendo-se em vista a posição central dos preços de capital e dos ativos financeiros na análise. Sobre os determinantes da taxa de câmbio, diz Arestis (2001, p. 162):

The main determinants of this relative price variable are the currently held views about the uncertain future. More concretely, the views of the speculators about movements in the ratio of short-term external debt to reserves will affect investors' expectations about the ability of the country to maintain the current price of its currency in relation to the price of capital and financial assets. Speculative attacks will almost certainly ensue, with exchange-rate readjustments being a distinct possibility, if not inevitability. Thus a financial crisis in Minsky's model could easily produce currency crisis.

O trabalho de Mathias (2008) tem por objetivo apresentar uma interpretação para as crises cambiais dos anos 90 ocorridas nos mercados emergentes da América Latina. O trabalho se apoia nos aspectos teóricos ressaltados pelo PPC Pós-keynesiano, com ênfase nos conceitos de incerteza, convenção e manada. Há 
também o respaldo da teoria de fragilidade financeira de H. Minsky, adaptada ao contexto de economias abertas. Há, portanto, um destaque para os elementos subjetivo (incerteza, convenção, etc.) e objetivo (as posturas referentes ao financiamento externo) que, em seu conjunto, explicam as crises dos anos 90.

Paula e Alves Junior (2000, p. 598) lembram que numa economia aberta em termos comerciais e financeiros: "[...] the exchange rate depends strongly on the actual and expected behavior of the balance of payments, which is an unplanned result of the action of autonomous agents". Os autores lembram que a taxa de câmbio depende fortemente do comportamento corrente e esperado do BP. Isto justifica a criação de um índice de fragilidade externa que capte a evolução do BP e indique a sua sustentabilidade. Concluem Paula e Alves Junior (2000, p. 598): "This is why it is important to calculate the degree of a country's external fragility: an evaluation of its dependence on refinancing in order to sustain the stability of its balance of payments and given exchange rate".

Resende e Amado (2007) procuram demonstrar que os ciclos de crescimento das economias periféricas (especificamente Brasil, México e Argentina) se comportam de modo reflexo aos ciclos da liquidez internacional. Para os citados autores as deficiências na estrutura produtiva e no sistema financeiro das economias periféricas aumentam a dependência de seu ciclo de crescimento em relação à sua receita de divisas externas. Além disso, para os autores as oscilações desta receita de divisas estão atreladas ao comportamento do sistema financeiro internacional. Este, por seu turno, demonstra-se tipicamente Minskyano ao adotar critérios para a concessão de crédito baseados na capacidade relativa esperada de cada economia em saldar seus compromissos financeiros externos.

\subsection{Momento 3: A Explicação da Crise Subprime e suas Repercussões Sistêmicas (2007-2008)}

Muitas abordagens foram construídas a partir do aparato teórico-analítico desenvolvido por Minsky para explicar a crise financeira de 2007 e 2008, iniciada com a crise subprime nos Estados Unidos. Em muitas delas foram feitas adaptações que levam em consideração o momento histórico, as mudanças institucionais e as inovações financeiras ${ }^{22}$.

No que tange ao desenvolvimento da abordagem de Minsky a partir da crise subprime, Vidotto (2008, p. 74) dá especial ênfase ao processo de securitização:

22 Convém ressaltar que nem todos os autores concordam com a adequação das ideias de Minsky para a explicação da crise subprime. Davidson (2008), por exemplo, sustenta que se não há movimento do financiamento hedge para o especulativo e Ponzi, uma pré-condição para o momento Minsky não ocorre, algo que, segundo o autor, não ocorreu na crise subprime. Vidotto (2008), por outro lado, sustenta que a crise à la Minsky no caso subprime não teve por epicentro o investimento das empresas e sim o mercado de hipotecas residenciais, dependendo, portanto, de canais adicionais para o entendimento da mesma, que passa pela securitização dos mercados financeiros. 
Incorporados os aspectos históricos pertinentes, essa abordagem [minskyana] [...] permite investigar o processo atual sem negar ou violentar seus traços essenciais. Um processo em que a economia tornou-se vulnerável a partir da fragilização ocorrida em um espaço de negócios a princípio secundário - o mercado de hipotecas subprime dos Estados Unidos - mas que envolvia, de forma silenciosa e progressiva, praticamente todo o sistema financeiro por meio dos mecanismos de securitização.

Kregel (2010, p. 2) leva em consideração as mudanças histórico-institucionais, ou seja, a evolução do sistema financeiro dos Estados Unidos na análise da crise subprime:

The fact that the subprime crisis was able to spread to the rest of the financial system and set off a full-scale bout of systemic instability and debt deflation is, however, the result of a Minsky process of sustained and increasing financial fragility in the rest of the financial system. To understand this process does not requires an analysis of the financial instruments implicated in the crisis, but of the evolution of the U.S. financial system, starting from the implementation and deterioration of Glass-Steagall New Deal legislation.

Kregel (2010) identifica duas mudanças estruturais. A primeira é o modo de financiamento dos negócios por meio dos mercados de capitais, em particular a securitização, que levou a uma integração das funções bancária e financeira ${ }^{23}$. A segunda é a maneira como as novas estruturas financeiras reduziram a liquidez do sistema e aumentaram a fragilidade em função do aumento da alavancagem financeira. Kregel (2010, p. 3) conclui:

This analysis leads to the conclusion that in a purely privately owned financial system it may be impossible to fully separate deposit-taking "commercial" banks from capital market activities if securitization is maintained as the basic structure used to provide financing to business and to other financial institutions. Nonetheless, it is possible to prevent banks from engaging in particular types of financial activities, in particular, proprietary trading and the financing of certain types of arbitrage trading that are not strictly related to the financing of business.

Sobre as crises financeiras Vercelli (2009, p. 3) afirma que: "Minsky's vision is able to cope with financial crisis because it clearly rejects the regularity assumption and is able to articulate an alternative vision in which disequilibrium, instability, lim-

23 Segundo Kregel (2010, p. 16): "In order to allow commercial banks to compete, regulators, legislators, and the judicial branch engaged in actions that opened the way to member banks' provision of these new innovations by allowing them increasing capital market activities that had been precluded under Glass. The end result was the almost complete erosion of the New Deal protections long before they were formally replaced by the Financial Modernization Act". 
ited rationality, and subjective features play a crucial role". Assim, o autor busca desenvolver extensões e desenvolvimentos da HIF à luz da crise financeira de 2007/8, em particular da subprime.

Vercelli (2009) leva em consideração a crescente "financeirização" da economia e a crescente participação de todas unidades econômicas (incluindo as famílias) no processo financeiro e aplica sua análise a todas essas unidades. $\mathrm{O}$ autor modifica uma das peças-chave da análise de Minsky, qual seja, a classificação das unidades financeiras. Isto permite, segundo Vercelli, uma simplificação e generalização do que ele acredita ser o núcleo duro da abordagem de Minsky, isto é, a interação entre as condições de liquidez e solvência entre as unidades econômicas isoladas e todo o setor privado.

\section{Considerações Finais}

Alterações de percurso são importantes para os programas de pesquisa científicos. Sobretudo quando se trata dos programas que por muito tempo foram alijados do debate macroeconômico. Tais alterações se aplicam ao PPC póskeynesiano, que a partir do desenvolvimento de hipóteses auxiliares pode voltar a avançar na capacidade de explicar melhor os fenômenos econômicos, mais especificamente macroeconômicos.

Com efeito, aperfeiçoamentos teóricos são bem-vindos. Parece que, por conta de momentos históricos singulares, tais aperfeiçoamentos vêm sendo observados no arcabouço proposto por Hyman Minsky, cuja capacidade de amoldar-se a circunstâncias histórico-institucionais dá a flexibilidade necessária para o desenvolvimento de uma heurística positiva dentro do programa de pesquisa pós-keynesiano.

Este trabalho destacou três momentos em que o PPC keynesiano recebeu aperfeiçoamentos por meio dos trabalhos de Minsky e seus seguidores. O último momento de aperfeiçoamentos da abordagem de Minsky é relacionado à crise subprime e seus desdobramentos. Foi justamente o momento do "retorno de Keynes" ou, ainda, o "momento Minsky". O que a revisão da literatura permite concluir é que tais aperfeiçoamentos continuarão a ocorrer, pois a capacidade explicativa das abordagens depende dos marcos histórico-institucionais nas quais se inserem.

Há, ainda, bastante espaço para o desenvolvimento das ideias relacionadas ao PPC pós-keynesiano. Portanto, o recente retorno das ideias de Keynes, sobretudo aquelas desenvolvidas por Minsky e seus seguidores, não parece sugerir um triunfo após uma derrota contundente, mas sim um momento de aperfeiçoamento do programa de pesquisa. Não há indícios de que o pensamento pós-keynesiano substituirá o pensamento macroeconômico dominante ("Novo Consenso") por causa somente da boa capacidade de explicação dos ciclos financeiros. O avan- 
ço e a disseminação do PPC pós-keynesiano depende de novos desenvolvimentos a guisa de permitir a concepção de novas explicações, nas inúmeras áreas do pensamento macroeconômico, com conteúdo empírico adicional, tornando-o progressivo novamente. É preciso o desenvolvimento de heurística positiva para que possa novamente avançar e, assim, voltar a recuperar terreno no debate macroeconômico.

\section{Referências}

ALVES JUNIOR, A. J.; FERRARI FILHO, F.; PAULA, L. F. R. The Post Keynesian critique of conventional currency crisis models and Davidson's proposal to reform the international monetary system. Journal of Post Keynesian Economics, Armonk, v. 22, n. 2. p. 207-225, Winter 1999-2000.

ARESTIS, P. Post-Keynesian economics: towards to coherence. Cambridge Journal of Economics, Oxford, v. 20, p. 111-135, Jan. 1996.

Recent banking and financial crises: Minsky versus the financial liberalizationists. In: BELLOFIORE, R.; FERRI, P. (Ed.). Financial keynesianism and market instability: the economic legacy of Hyman Minsky. Cheltenham: E. Elgar, 2001. Vol. I, p. 159-178.

BASTOS, P. P. Z. Readaptando a hipótese da instabilidade financeira (Minsky está morto?). Leituras de Economia Política, Campinas, n. 3, p. 221-233, dez. 1996.

BLANCHARD, O.; DELL'ARICCIA, G.; MAURO, P. Rethinking Macroeconomic Policy. IMF Staff Position Note, Feb. 2010.

BLAUG, M. Metodologia da Economia. São Paulo: Ed. da USP, 1999.

CARVALHO, F. J. C. Mr. Keynes and the post keynesians: principles of macroeconomics for a monetary production economy. Aldershot: E. Elgar, 1992.

O retorno de Keynes. Novos Estudos, São Paulo, n. 83, p. 91-101, mar. 2009.

COSTA, F. N. Ensaios de economia monetária. São Paulo: Bienal, 1992.

DAVIDSON, P. Is the current financial distress caused by the subprime mortgage crisis a Minsky moment?: or is it the result of attempting to securitize illiquid noncommercial mortgage loans? Journal of Post Keynesian Economics, Armonk, v. 30, n. 4, p. 669-676, July 2008.

DELLI GATTI, D.; GALLEGATI, M. Financial instability, income distribution, and the stock market. Journal of Post Keynesian Economics, Armonk, v. 12, n. 3, p. 356-374, Spring 1990.

DEQUECH, D. Uncertainty, conventions and short-term expectations. Brazilian Journal of Political Economy, São Paulo, v. 19, n. 3, p. 67-81, July/Sep. 1999.

DOWNE, E. A. Minsky's Model of Financial Fragility: a suggested addition. Journal of Post Keynesian Economics, Armonk, v. 9, n. 3, p. 440-454, Spring 1987.

DYMSKI, G. "Economia de bolha" e crise financeira no leste asiático e na Califórnia: uma perspectiva espacializada de Minsky. Economia e Sociedade, Campinas, v. 11, p. 73-136, dez. 1998.

FOLEY, D. K. Hyman Minsky and the dilemmas of contemporary economic method. New York: Columbia Universisty, 1998. Mimeo. 
. Financial Fragility in Developing Economies. In: DUTT, A. K.; ROS, J. Development economics and structuralist macroeconomics: essays in honor of Lance Taylor. Cheltenhan: E. Elgar, 2003, p.157-168.

HERMANN, J. Fragilidade financeira do setor público: implicações para a gestão da política econômica. 1993. Dissertação (Mestrado em Economia) - Instituto de Economia Industrial, Universidade Federal do Rio de Janeiro, Rio de Janeiro, 1993.

KEYNES, J. M. Teoria geral do emprêgo do juro e do dinheiro. 2. ed. Lisboa: Fundo de Cultura, 1970.

KINDLEBERGER, C. P. Manias, pânico e crashes: um histórico das crises financeiras. Rio de Janeiro: Nova Fronteira, 2000.

KREGEL, J. Yes, "it" did happen again: a Minsky crisis happened in Ásia. Leuy Economics Institute Working Paper, Annandale-on-Hudson, n. 234, p. 1-19, Apr. 1998. Disponível em: <http://www.levyinstitute.org/pubs/wp234.pdf>. Acesso em: 21 jan. 2000.

Is This the Minsky Moment for Reform of Financial Regulation? Leuy Economics Institute Working Paper, Annandale-on-Hudson, n. 586, Feb. 2010.

KRUGMAN, P. How did economists get it so wrong? 2009. Disponível em: < http://www.nytimes.com/2009/09/06/magazine/06Economic-t.html?_r>. Acesso em: 10 dez. 2009.

LAKATOS, I. Falsificação e metodologia dos programas de investigação científica. Lisboa: Edições 70, 1978.

LARA RESENDE, A. A ruptura do mercado internacional de crédito. In: ARIDA, P. (Org.). Dívida externa, recessão e ajuste estrutural. Rio de Janeiro: Paz e Terra, 1982. p. 41-54.

LAVOIE, M. Systemic financial fragility: a simplified view. Journal of Post Keynesian Economics, Armonk, v. 9, n. 2, p. 258-266, Winter 1986-1987.

LOURENÇO, A. L. C. O pensamento de Hyman P. Minsky: alterações de percurso e atualidade. In: ENCONTRO NACIONAL DE ECONOMIA, 33., 2005, Natal. Anais... Natal: ANPEC, 2005.

MATHIAS, J. F. C. M. Abordagem sistêmica de crises cambiais: uma interpretação da crise brasileira de 1999. 2003. Tese (Doutorado em Economia da Indústria e da Tecnologia) - Instituto de Economia, Universidade Federal do Rio de Janeiro, Rio de Janeiro, 2003.

. Crises cambiais: uma abordagem keynesiana. In: ENCONTRO DA ASSOCIAÇÃO KEYNESIANA BRASILEIRA, 1., 2008, Campinas. Anais... Campinas: AKB, 2008.

MINSKY, H. P. John Maynard Keynes. New York: Columbia University Press, 1975. . John Maynard Keynes. New York: Mc Graw-Hill, 2008.

$\overline{1982 .}$ . Can "it" happen again?: essays on instability and finance. New York: M. E. Sharpe, . Stablizing an unstable economy. New Haven: Yale University Press, 1986.

Stablizing an unstable economy. New York: McGraw-Hill, 2008.

. The financial instability hypothesis. Leuy Economics Working Paper, Annandale-onHudson, n. 74, p. 1-10, May 1992.

. Financiamento e lucro. Cadernos ANGE, Niterói, 1992b.

MIRANDA, J. C. Apresentação. Economia e Sociedade, Campinas, n. 4, p. 3-9, jun. 1995. 
OREIRO, J. L. Economia Pós-Keynesiana: origem, programa de pesquisa, questões resolvidas e desenvolvimentos futuros. In: ENCONTRO NACIONAL DE ECONOMIA, 36., 2008, Niterói. Anais... Niterói: Anpec, 2008.

PAULA, L. F. R.; ALVES JUNIOR, A. J. External financial fragility and the 1998-1999 Brazilian currency crisis. Journal of Post Keynesian Economics, Armonk, v. 22, n. 4. p. 589-617, Summer 2000.

PAULA, L. F. R.; FERRARI FILHO, F. Tempos keynesianos. In: ASSOCIAÇÃO KEYNESIANA BRASILEIRA. Dossiê da Crise II. 2010. Disponível em: <http://www.ppge.ufrgs.br/akb>. Acesso em: 05 mar. 2011.

RESENDE, M. F. C.; AMADO, A. M. Liquidez internacional e ciclo reflexo: algumas observações para a América Latina. Revista de Economia Política, São Paulo, v. 27, n. 1, p. 41-59, jan./mar 2007.

SEMMLER, W. A macroeconomic limit cycle with financial perturbations. Journal of Economic Behavior and Organization, Amsterdam, v. 8, n. 3, p. 469-495, Sep. 1987

SICSÚ, J.; SOBREIRA, R; SHULTZ, V. Uma nota introdutória ao artigo "Financiamento e Lucros" de H.Minsky. Cadernos Didáticos ANGE, n. 2, 1992.

SILVA, M. L. F. Âncora cambial e programas de estabilização na América Latina: considerações gerais. In: ENCONTRO DE ECONOMISTAS DE LÍNGUA PORTUGUESA, 4., 2001, Évora. Anais... 2001. 1 CD-ROM.

SKIDELSKY, R. Keynes: the return of the master. New York: PublicAffairs, 2009.

SNOWDON, B.; VANE, H. R. Modern macroeconomics: its origins, development and current state. Cheltenham: E. Elgar, 2005.

STUDART, R. The Efficiency of Financial Systems. Journal of Post Keynesian Economics, Armonk, v. 18, n. 2, p. 269-292, Winter 1995-1996.

TAYLOR, L.; O'CONNELL, S. A. A Minsky crisis. The Quarterly Journal of Economics, Cambridge, Mass, v. 100, Supplement, p. 871-885, 1985.

TYMOIGNE, E. Minsky and economic policy: "keynesianism" all over again? Leuy Economics Working Paper, Annandale-on-Hudson, n. 547, p. 1-41, Oct. 2008.

VERCELLI, A. A perspective on Minsk moments: the core of the financial instability hypothesis in light of the subprime crisis. Leuy Economics Working Paper, Annandale-on-Hudson, n. 579, Oct. 2009.

VIDOTTO, C. O espectro de Keynes ronda a América: hipotecas, securitização e crise financeira nos Estados Unidos. In: SICSÚ, J.; VIDOTTO, C. (Org.). Economia do Desenvolvimento: teoria e políticas Keynesianas. Rio de Janeiro: Campus, 2008. p. 46-76.

VIEIRA, J. G. S. A estrutura das revoluções científicas na economia: a constituição do paradigma keynesiano e sua crise. 2002. Dissertação (Mestrado) - Programa de Pós-Graduação em Desenvolvimento Econômico, Universidade Federal do Paraná, Curitiba, 2002.

Recebido em: 09/09/2010.

Aceito em: 15/09/2011. 